\title{
Knowledge of the Edinburgh Postnatal Depression Scale among psychiatrists and general practitioners
}

\author{
Peter Aitken and Robin Jacobson
}

\begin{abstract}
The alm was to examine the impression that both general practitioners and psychiatrists have a low level of awareness and knowledge of the Edinburgh Postinatal Depression Scale (EPDS), have little experience in its use, and would not feel confident in olving advice on issues arising from its use by health visttors.
\end{abstract}

Postnatal depression (PND) is a common condition affecting mothers following $10-15 \%$ of all deliveries (Kumar \& Robson, 1984) and is poorly recognised for several reasons. Healthcare professionals are found to concentrate on physical illness and the baby, and so neglect maternal mental health (Goldberg, 1992). Mothers feel guilty about discussing their ambivalent and negative feelings with partners and health professionals. Its recognition is important since the associated morbidity not only adversely affects the mother (Watson et al, 1984) but also the developing child (Murray \& Stein, 1989). It is important to promote awareness and increase detection of PND, which is readily treatable.

The Edinburgh Postnatal Depression Scale (EPDS) is a research screening instrument developed by Cox and co-workers (1987) in Edinburgh and consists of a ten-item selfreport questionnaire. It has high specificity and sensitivity for identifying possible cases of postnatal depression, which are then diagnosed by clinical interview. It has been validated as a research screening instrument for use within the UK population (Cox et al, 1987) and within most Western cultures. although cross-cultural research outwith western Europe and North America remains in its infancy (O'Hara, 1994). It has been used and validated in clinical practice in the UK primary care setting where it should be administered by a health professional experienced in its use, most often a health visitor. In clinical use there is a need for clearly identified referral systems (Holden, 1994) to manage cases scoring highly $(>12 / 13)$ on the EPDS which correlate with PND.

As part of their continuing professional development, health visitors in our local health district have been instructed in the use of the EPDS and taught non-directive counselling skills (Holden, 1989) with the aim of improving the recognition, assessment and management of PND. They have adopted the EPDS for general clinical use. Their expectation is that general practitioners (GPs) and psychiatrists in our area will be familiar with the EPDS and its use and be able to give advice on issues arising.

The GPs and psychiatrists from whom they might expect advice and support are anecdotally reported to be unfamiliar with the instrument or the rationale for its use. We surveyed GP and psychiatrist knowledge of the EPDS.

\section{The study}

A letter/questionnaire was sent to 173 psychiatrists at all grades in the St George's Hospital training rotation, including 39 consultant psychiatrists based within St George's Hospital and Pathfinder Mental Health NHS Trust, 48 senior registrars, and the remainder registrars, senior house officers and non-consultant grades who either worked within St George's Hospital or Pathfinder Mental Health NHS Trust, or who would rotate there as part of training and may be subject to the St George's academic programme, their clinical commitments being within Merton. Sutton and Wandsworth. London. We also wrote to 350 of the 353 principals in general practice listed with the Merton. Sutton and Wandsworth Health Authority.

The letter/questionnaire described the reason for the inquiry and asked the respondent to answer five questions. These were:

(1) I am aware of the Edinburgh Postnatal Depression Scale (Yes/No). 
(2) I have used the Edinburgh Postnatal Depression Scale (Yes/No).

(3) A score of 14 represents health (Yes/No/ Don't know).

(4) I would feel confident now to give advice on issues arising from the use of the Edinburgh Postnatal Depression Scale (Yes/ No).

(5) What issue does question 10 address? (or indicate don't know).

The reply letter was anonymous except that respondents could be identified as GPs or psychiatrists. All were provided with an addressed envelope in which to return the completed questionnaire. Respondents were invited to identify themselves on a separate piece of paper only if they wished to receive further information on the EPDS.

\section{Findings}

Table 1 shows the response rate to the survey, and Table 2 the survey results. Only 57 (46\%) psychiatrists and 47 (33\%) GP respondents were aware of the EPDS. In both groups, fewer than $6 \%$ of respondents had used the scale or were happy to advise on issues arising from its use. Less than $6 \%$ could identify the nature of question 10, the suicide/self-harm item. Marginally more (6\%) identified a total score of 14 as not indicating health.

\section{Comment}

The letter/questionnaire was restricted to one side of A4 and styled to require the best response to be ringed for the first four questions, with a written response only required for the fifth. Response rates to the questionnaire letter were good for psychiatrists $(\mathbf{7 1 \% )}$ and poorer for GPs (41\%), the latter in keeping with the limitations of the postal questionnaire for surveys (Bennett \& Ritchie, 1975).

The difference in response rates between psychiatrists and GPs could be explained by non-enclosure of a stamp on the self-addressed envelope to GPs. The majority of psychiatrists replied by internal post.

The psychiatrist group contained trainees who may have more time and inclination to answer research questionnaires. Assessing the number of consultant replies was only possible for those who identified their status when requesting further information - 7 out of the 39 .

GPs and psychiatrists vary in their attitudes to mental illness, reflecting their different experience in practice (Kerr et al, 1995). GPs are found to be more inclined to audit care of physical illness than psychiatic illness, possibly because of the lack of objective measures of psychiatric disorder available for use in general practice (Wright \& Anderson, 1995). Psychiatrists should be familiar with the use of psychiatric assessment instruments.

\section{Conclusions}

This study indicates a remarkably low level of knowledge, skill and familiarity with the EPDS among GPs and psychiatrists in the Merton. Sutton and Wandsworth health authority area. It is unlikely that either professional group, without further training, could support health visitors in the use of the EPDS.

There is an urgent need to embark on training for GPs and community mental health team (CMHT) psychiatrists in the use of the EPDS, and to provide specialist advice when requested. This approach would have the attraction of including a wider body of healthcare professionals in the recognition and management of PND, using and enhancing skills already possessed, and reducing the number of specialist referrals. The cost involved in providing the educational opportunity to GPs and psychiatrists should be considered in relation to the cost of health visitors using a scale which, without opportunity for further treatment, is of no benefit to the mother.

Expansion of tertiary mother and baby psychiatry services could include direct routes of communication and referral for health visitors using the EPDS. This has the advantage of making specialist knowledge directly available to the primary healthcare worker, but has two disadvantages. First, it may bypass and potentially de-skill GPs and CMHT psychiatrists. Second, it may generate inappropriate referrals that could be assessed and managed adequately

Table 1. Response rates to the survey

\begin{tabular}{lll}
\hline Response rate & Psychiatrists & GPs \\
\hline Questionnaires sent & 173 & 350 \\
Response rate & 123 (71\%) & 144 (41\%) \\
\hline
\end{tabular}

Table 2. Results of survey response to questions

\begin{tabular}{lcc}
\hline Of respondents & Psychiatrists & GPs \\
\hline Requested information & $46(37 \%)$ & $59(41 \%)$ \\
Aware of scale & $57(46 \%)$ & $47(33 \%)$ \\
Had used scale & $5(4 \%)$ & $8(6 \%)$ \\
Correct 'score 14' & $4(3 \%)$ & $11(8 \%)$ \\
Confident to advise & $6(5 \%)$ & $6(5 \%)$ \\
Correct question 10 & $3(2 \%)$ & $6(5 \%)$ \\
All five correct & $3(2 \%)$ & $6(5 \%)$ \\
\hline
\end{tabular}




\section{ORIGINAL PAPERS}

in the primary care setting, without overburdening the specialist service.

The initiative from health visitors is welcome. Experience and knowledge of the EPDS should advance through its wider clinical use and inclusion in local education programmes. Health visitors must exercise extreme caution in using a screening instrument in an area where support from other agencies is uninformed or unavailable. This can be overcome by close liaison with specialist mother and baby mental health services in joint initiatives to inform and support GPs and community mental health teams.

\section{References}

BENNETT, A. E. \& RrTCHIE, K. (1975) The self administered questionnaire. In Questionnaires in Medicine - A Guide to Their Design and Use, pp. 55-58. London: Oxford University Press.

COX, J. L. HOLDEN, J. M. \& SAGovSKY, R. (1987) Detection of post-natal depression: development of the Edinburgh Postnatal Depression Scale. British Journal of Psychiatry, 150. 782-786.

GOLDBERG, D. (1992) Early diagnosis and secondary prevention. In Prevention of Anudety and Depression in General Practice (ed. R. Jenkins), pp. 33-39. London: HMSO.

HOLDEN, J. (1994) Using the Edinburgh Postnatal Depression Scale in clinical practice. In Perinatal Psychiatry-Use and Misuse of the Edinburgh Postnatal Depression Scale (eds J. Cox \& J. Holden). p. 133. London: Gaskell.

-. SAGOVSKY, R. \& CoX, J. L. (1989) Counselling in general practice setting: controlled study of health visitors intervention in treatment of postnatal depression. British Medical Joumal, 298, 223-226.
KERR, M., Bluzard, R. \& Mann, A. (1995) General practitioners and psychiatrists: comparison of attitudes to depression using the depression attitude questionnaire. British Journal of General Practice, 45. 89-92.

KUMAR, R. \& RoBson K. M. (1984) A prospective study of emotional disorders in child bearing women. British Journal of Psychiatry. 144. 35-47.

MURRAY, L. \& STEIN, A. (1989) The effects of postnatal depression on the infant. In Psychological Aspects of Obstetrics and Gynaecology (ed. M. R. Oates), pp. 921935. London: Baillière-Tindall.

O'HARA, M. W. (1994) Postpartum depression: identification and measurement in a cross-cultural context. In Perinatal Psychiatry-Use and Misuse of the Edinburgh Postnatal Depression Scale (eds J. Cox \& J. Holden), pp. 145-168. London: Gaskell.

WATSON, J. P., Eluott, S. A., RugG, A. J., et al (1984) Psychiatric disorders in pregnancy and the first postnatal year. British Journal of Psychiatry 144. 453462.

WRIGHT, A. F. \& ANDERSON, A. J. B. (1995) Newly identifled psychiatric illness in one general practice: 12 month outcome and the influence of the patients' personality. Brttish Journal of General Practice, 45, 89-92.

*Peter Aitken, Clinical Lecturer in Adult Psychiatry and Robin Jacobson, Senior Lecturer in Perinatal Psychiatry, Section of Psychosomatic and Liaison Medicine, Department of Adult Psychiatry, Jenner Wing, St George's Hospital Medical School, Cranmer Terrace, London SW17 ORE

*Correspondence 